\title{
Bibliografia mexicana de arte
}

\author{
1995 \\ por \\ XAVIER MOYSSÉN
}

La producción de libros dedicados al atte de México durante 1995 no fue considerable en relación con años anteriores. Las causas se encuentran en la crisis económica por la que atraviesa el país. Sin embargo, los libıos que se publicaron constituyen valiosas aportaciones a la historia del arte mexicano: sus autores entregaron en sus páginas el producto de una experiencia personal de estudio y meditaciones ante las obras mismas. Varios son los temas estudiados, los cuales se han reunido en grupos para presentarlos aquí. Antes de seguir adelante deseo subrayar la alta calidad que alcanzaron los libros en su impresión, bien sean los que reproducen las obras en blanco y negro, bien lo que lo hicieron en colores; ciertos libros producidos aquí compiten con algunos hechos en el extranjero.

Los estudios dedicados a la arquitectura ofrecen una amplia visión sobre lo que es sobresaliente en el arte edilicio de las distintas latitudes del país. Sobre ello entrega una idea limitada, por el espacio editorial de que dispuso, Enrique X de Anda Alanís en su Historia de la arquitectura mexicana. Una labor valiosa es la que ha emprendido Graciela de Garay con la Historia oral de la ciudad de México. Testimonios de sus arquitectos, I940-1990. En realidad se trata de entrevistas que De Garay ha hecho para publicarlas en prácticos cuadernos. El segundo que ha apa- recido está dedicado a Abraham Zabludovsky. Es una excelente introducción para comprender la obra del famoso arquitecto.

Obras de una gran utilidad, pues demuestran en conjunto lo que es la arquitectura actual de México, son las siguientes: de Ernesto Ayala Martínez, La casa en la arquitectura mexicana y La tercera bienal de arquitectura mexicana, y la debida a varios autores titulada La arquitectura de la Ciudad Universitaria; esta última tiene un singular mérito, pues sus textos fueron escritos únicamente por arquitectos. Se publicaron también estudios monográficos sobre arquitectos en particular, como el muy merecido que Louise Noelle escribió sobre el maestro Vladimir Kaspé Reflexión y compromiso; he anotado que muy merecido por la entrega que Kaspé ha hecho de su vida desde 1942, año en que arribó a México para iniciar una fructífera labor que está lejos de haber concluido. Otro libro dedicado a un solo personaje y a un aspecto de su extensa obra es el debido a Ramón Vargas Salguero, en que el estudia los Pabellones y museos de Pedro Ramirez Vazquez, edificios con los que ha alcanzado la celebridad de que disfruta.

En esta bibliografía se incluye un buen número de catálogos publicados a propósito de tal o cual exposición. En muchas ocasiones, estos catálogos son en realidad libros de arte: sus textos han sido redactados por críti- 
cos e historiadores profesionales y sus juicios poseen una validez comparable a los que se encuentran en los libros. ¡Por fin el Diario de Frida Kablo puede ser consultado con toda libertad! La edición lleva un texto introductorio de Carlos Fuentes, amén de algunos ensayos debidos a otros autores. Por su parte, María Teresa Favela Fierro escribió un libro dedicado a Jorge González Camarena. Universo plástico, en el cual oftece una serie de consideraciones originales sobre el controvertido pintor de cuadros de caballete y murales. Renato González Mello hizo su debut como investigador inquieto, con su obra Orozco. ¿Pintor revoluciondrio? Buena presentación para iniciar una carrera que espero sea fructífera.

"Frontera de la modernidad" es el título del texto que escribió Alberto Híjar para el catálogo de la exposición Zalce total, en la que se reunió la obra pictórica, gráfica, escultórica y magisterial de Alfredo Zalce. Fue analizada por Híjar desde su personal criterio estético, que tiene por base la ideología; el texto responde a los fines perseguidos en la exposición de homenaje al attista michoacano. Un excelente catálogo de exposición es Testimonios artísticos de un episodio fugaz 1864-1867, referida al imperio de Maximiliano, en la que se dieron a conocer obras poco divulgadas; el catálogo cuenta con una serie de estudios de primer orden, como los debidos a Fausto Ramírez y Esther Acevedo

A la autorizada pluma de Raquel Tibol se debe el texto del catálogo de la exposición Rufino Tamayo. Del reflejo al sueño igzo1950. Las obras seleccionadas para esta exposición confirman la trayectoria creativa de Tamayo. Otro catálogo con textos escritos por varios autores es el que se publicó a propósito de la exposición Joaquín Clausell y los ecos del impresionismos en México. Estos textos contribuyen a un entendimiento conclusorio sobre la pintura del gran paisajista.

Entre los libros que se publicaron en I995 se encuentra uno de singular importancia, pues en él se dan a conocer por primera vez las pinturas y dibujos que forman la riquísima colección que en el correr de los años formó, de acuerdo con un propósito, el ingeniero Pascual Gutiérrez Roldán. La aparición de este libro debiera mover a otros coleccionistas a seguir su ejemplo. Con el título de Aire de familia, fue presentada la colección de caricaturas reunidas por Carlos Monsivais. Cierro esta sucinta relación sobre los libros más significativos dedicados al arte contemporáneo reunidos en este grupo, con la monumental obra que presenta Los murales del Palacio de Bellas Artes, con estudios de cada una de las pinturas, debidos a críticos e historiadores autorizados para escribir sobre murales. Todos se reprodujeron a gran tamaño e impresos a color con esmerado cuidado. Un libro semejante a éste debió publicarse hace tiempo, como reconocimiento a la gran contribución de México al arte del presente siglo.

Los estudios sobre el arte colonial bajaron en importancia en relación con el númeto de los publicados en años anteriores. Dos títulos sobresalen de esa breve producción, y los dos se ocupan de la pintura: el pinineto se debe a Guillermo Toyar de Teresa, quien se dedicó a analizar la obra de Miguel Cabrera, en tanto que el autor del segundo es el malogrado José Guadalupe Victoria, cuyo libro póstumo es Un pintor en su tiempo, Baltazar de Echave Orio. En esta obra, Victoria recogió las noticias conocidas del célebre pintor del siglo xvi, las cuales ordenó en el estudio que hizo de los cuadros que de él subsisten, cuadros origi- 
nales y también los que le son adjudicados; sobre estos últimos, Victoria tuvo la capacidad crítica para aceptarlos o rechazarlos.

Beatriz de la Fuente es autora de una extensa obra que se significa en los estudios del arte prehispánico, por la responsabilidad de sus juicios, por las exhaustivas investigaciones que realiza tanto en los sitios arqueológicos, museos y colecciones particulares, como en el gabinete de estudio. En el Instituto de Investigaciones Estéticas de la UNAM dirige un seminario sobre la pintura mural prehispánica, cuyo primer producto fue el catálogo de las sorprendentes pinturas murales de Teotihuacan, sometidas a análisis por cada uno de los integrantes del seminario. Una obra como ésta era necesario que se emprendiera, y los resultados son magnífcos, como puede constatarse en el diseño y la edición del libto. El catálogo de la exposición presentada en el Antiguo Colegio de San Ildefonso sobre los Dioses del México antiguo reúne una serie de consideraciones sobre el arte escultórico en torno a las deidades representadas. Los textos se deben tanto a Eduardo Matos Moctezuma como a los colaboradores que con él fueıon responsables de la formidable muestra.

Un libro singular entre los que se han publicado en los últimos años, por el planteamiento teórico que ofrece, es el de Dúrdica Šégota, Valores plásticos del arte mexica. El libro en sü rico contenido tiene como base sustentante la imagen de Iláloc y los hallazgos habidos en las excavaciones del Templo Mayor de Tenochtitlan. Finalizo esta reseńa sobre los libros dedicados al arte antiguo, con El oro precolombino de México, del que son autores Felipe Solís y Martha Carmona: las noticias que ofrecen en sus textos renueva el tema que no se había tratado desde hace algunos años, y la edición en formato mayor permite, a través de las ilustraciones, formarse una idea del valor de la orfebrería prehispánica.

Los libros dedicados a la fotografía fueron escasos, pero los publicados cubren esa ausencia mediante los méritos de sus contenidos y con la calidad de sus impresiones. Así por ejemplo Luz y tiempo, que en tres volúmenes muestra la colección fotográfica formada por Manuel Álvarez Bravo para la Fundación Cultural Televisa. El conocimiento que posee de la historia de la forografía y sus principales exponentes permitió a Álvatez Bravo formar esta espléndida colección con muestras de maestros como Paul Strand, August Sander, Edward Steichen, Alfred Stieglitz, Clarence H. White, Dorotea Lange, Gertude Kasebier, Roger Fenton, Berenice Abbot, Hippolyte Bayard, Brassai y otros más; la colección incluye, por supuesto, una selección de fotografías del propio Álvarez Bravo. La publicación de este catálogo ha sido todo un acierto, como también lo ha sido el libro-homenaje dedicado a Kati Horna, con una selección de sus obras y un texto en el que Emma Cecilia García Kinsky hace la presentación de la artista de la lente. El pie de imprenta acusa que el estudio de Francisco Montellano fue impreso en 1994; el libro, sin embargo, circuló hasta el año siguiente, por tal razón se incluye aquí Se trata de la investigación que Montellano realizó sobre el fotógrafo norteamericano C.B. White, activo en México a principios de este siglo, figura poco menos que desconocida, sobre la cual se han reunido un buen número de fotografías que nos permiten conocer aspectos perdidos de México.

He agrupado algunos libros bajo el título de "Temas varios", entre los que se encuentran los dedicados al estudio de la 
Danza en México, debido a la autoridad en el tema, Alberto Dallal. Se trata de dos volúmenes, el primero dedicado a un Panorama crítico y el segundo a La danza escénica popular, 1877-1930. Cuando Dallal termine con sus investigaciones podremos contar con una obra imprescindible: la historia de la danza mexicana. El arte de la herrería en México, obra escrita por Guillermo Tovar de Teresa y Efraín Castro Morales, es el resultado de las investigaciones realizadas tanto en los archivos como ante las obras mismas, por dos historiadores del atte que en este libro rescatan las manifestaciones artísticas del hierro forjado. Finalmente, he incluido en este apretado resumen las memorias de las ponencias presentadas en los coloquios internacionales de historia del arte, organizados por este Instituto.

\section{Arquitectura}

Alva Martínez, Ennesto, La casa en la arquitectura mexicana México, COMEX, 1995

Anda Alanís, Enrique X de, Historia de la arquitectura mexicana. México-Barcelona, Gustavo Gili, I995.

La arquitectura de la Ciudad Universitaria México, Universidad Nacional Autónoma de México-Facultad de Arquitectura, 1995 .

Catálogo nacional de monumentos históricos inmuebles. Estado de Tlaxcala México, Gobierno del Estado de Tlaxcala-Instituto Nacional de Antropología e Historia-Secretaría de Desarrollo Social, 1995, 3 vols

Catálogos de arquitectura mexicana. Agustín Hernández. Introducción y textos de Louise Noelle, México-Barcelona, Gustavo Gili, I995.
Garay, Graciela de, Abraham Zabludousky Historia oral de la ciudad de México. Testimonios de sus arquitectos (19401990) México, Instituto de Investigaciones Dr. José María Luis Mora, 1995

Mijares, Enrique, Patrimonio arquitectónico de la ciudad de Durango. Durango, CopPAC, 1995

Noelle, Louise, Myth and Modernism in Mexican Architecture. Catálogo de la exposición del Visual Arts Center, Fulletton, California State University, 1995

- Vladimir Kaspé Reflexión y compromiso. México, Universidad La Salle, I995

Sánchez Arquitectos y Asociados: Catálogos de arquitectura mexicana. México, Gustavo Gili, I995.

Vallarino, Roberto, Pedro Ramírez Vázquez Museums, 1952-1994. Edición de Beatrice Trueblood, México, 1995.

Vargas Salguero, Ramón, Pabellones y museos de Pedro Ramirez Vázquez. México, Noriega, 1995.

Woods, Lebbeus, Ten arquitectos. Taller de Enrique Norten Arquitectos. MéxicoBarcelona, Gustavo Gili, 1995.

\section{Arte conemporáneo}

Aire de familia Colección de Carlos Monsiváis. Catálogo de la exposición del Museo de Arte Moderno, México, Consejo Nacional para la Cultura y las Artes-Instituto Nacional de Bellas Artes, I995.

Bayón, Damián, Hacia Rufino Tamayo. México, Fundación Olga y Rufino Tamayo-Fondo de Cultura Económica, 1995. 
Bilder und Visonen. Mexikanische Kunst Zwschea Avangarde und Aktualität. Catálogo de la exposición del Museo Würth de Kunzelsau (Alemania), 1995.

Bodas del cielo y del infierno. Catálogo de la exposición de Arturo Rivera en el Museo de Arte Moderno, México, Sociedad Mexicana de Arte ModernoConsejo Nacional para la Cultura y las Artes-Instituto Nacional de Bellas Artes, I995.

Brehme, Hugo, México, una nación persistente. México, Instituto Nacional de Bellas Artes, 1995

Cabañas Bravo, Miguel, El ocaso de la política artística americanista del franquismo, la imposible continuidad de las bienales Hispano-Americanas de Arte. México, Instituto Mexiquense de Cultura, I995.

Colectión Mathías Goeritz. Guadalajara, Instituto Cultural Cabañas, 1995

Colección Pascual Gutiérrez Roldán. México, Attame, 1995.

Conde, Teresa del, y Edward J. Sullivan, Arnaldo Roche Rabel. Catálogo de la exposición del Museo Arte Moderno, México, Consejo Nacional para la Cultura y las Artes-Puerto Rico Compañía de Turismo-Instituto Nacional de Bellas Artes-Fundación Cultural Gallo, I995.

Edward, Lucie Smith, y Horacio Ferrer, Leonardo Nierman. Pintura, escultura, tapiz, rg89-I994. México, Consejo Nacional para la Cultura y las ArtesInstituto Nacional de Bellas Artes, 1995

Expresión plástica. 35 artistas en Veracruz. Xalapa, Gobierno del Estado de Veracruz, 1995 .

Favela Fierro, María Teresa, Jorge González Camarena. Universo plástico. México, Democracia, 1995
Fernández Ledesma, Enrique, Nueva galería de fantasmas. México, Universidad Nacional Autónoma de México, 1995. Frida Kablo. Didrio Autorretrato intimo. Facsímile, introducción de Carlos Fuentes, ensayos de Karen Cordero, Olivier Debroise, Sarah M. Lowe y Graciela Martínez-Zalce, México, La Vaca Independiente, 1995.

García Barragán, Elisa, Emilia Ortiz, vida y obra de una pintora apasionada. Tepic, Fundación Alica de Nayarit, I995.

González Mello, Renato, José Clemente Orozco. Guadalajara, Instituto Cultural Cabañas, I995.

—_, Orozco ¿̨intor revolucionanio? México, Universidad Nacional Autónoma de México-Instituto de Investigaciones Estéticas, 1995.

Henestrosa, Andrés, Los hombres que dispersó la danza. México, Celanese Mexicana, 1995 .

Homenaje a Rodolfo Nieto, 1936-1985. México, Museo de Arte Contemporáneo de Monterrey, I995.

Jalisco genio y maestría. México, Museo de Arte Contemporáneo de Montertey, 1995.

Joaquín Clausell y los ecos del impresionismo en México. Catálogo de la exposición del Museo Nacional de Arte, México, Patronato del Museo Nacional de ArteConsejo Nacional para la Cultura y las Artes-Instituto Nacional de Bellas Artes, 1995.

Kassner, Lily, Armando Morales. México, Américo Arte Editores, 1995,

Kim, Sojin Chucano, Graffiti and Murals. The Neighborbood Art of Peter Quezada. University of Mississippi, I995

Legado de Luis Barragán. Guadalajara, Secretaría de Cultura de Jalisco, 1995. 
Medina, Cuauhtémoc, et al., Acné o el nuevo contrato social ilustrado. Catálogo de la exposición del Museo de Arte Moderno, México, Consejo Nacional para la Cultura y las Artes-Instituto Nacional de Bellas Artes, I995.

Mesa, Guiomar, $E l$ salón de los objetos perdidos. México, Museo de Arte Contemporáneo de Montetrey, i995.

Moyssén, Xavier, Joaquín Clausell: la casa de las mil ventanas. México, Teléfonos de México, I995

Los murales del Palacio de Bellas Artes. México, Américo Arte Editores-Consejo Nacional para la Cultura y las ArtesInstituto Nacional de Bellas Artes, 1995.

Ortiz Angulo, Ana, La pintura mexicana independiente de la academia del siglo $X I X$. México, Instituto Nacional de Antropología e Historia, I995.

Piero, Joan Bta, Nova gafica mexicana. Alcoi, Centre Cultural D'Alcoi, 1995.

Pimentel, Rodrigo, Testigos ausentes Catálogo de exposición, México, Instituto Nacional de Bellas Artes, 1995 .

Rafael Cauduro dibujos. Catálogo de la exposición del Museo Nacional de la Estampa, México, Consejo Nacional para la Cultura y las Artes-Instituto Nacional de Bellas Artes-Lotería Nacional, 1995

Ramírez, Fausto, et al, Testimonios artísticos de un episodio fugaz (I864-I867). Catálogo de la exposición del Museo Nacional de Arte, México, Consejo Nacional para la Cultura y las Artes-Instituto Nacional de Bellas Artes, 1995.

Recordando a Fernando Gambod. México, Instituto Nacional de Bellas Artes, 1995.

Reyna, María del Carmen, Tacuba y sus alrrededores: siglos $X V I-X X$. México, Instituto Nacional de Antropología e Historia, 1995
Ruiz Soto, Alfonso, Rafael Cauduro. De ángeles, calvarios, calaveras y otras calamidades. Catálogo de la exposición del Museo del Palacio de Bellas Artes, México, Vid-Consejo Nacional para la Cultura y las Artes-Instituto Nacional de Bellas Artes, 1995

Sánchez Laurel, Herlinda, Juegos de luz y niebla. Catálogo de exposición, México, Instituto Nacional de Bellas Artes, 1995

Sánchez Mena, Rogelio, El art decó en León, Gudnajuato. México, Instituto Nacional de Antropología e Historia, I995.

Schneider, Luis Mario, Abraham Angel. Toluca, Instituto Mexiquense de Cultura, I995.

—, José Maria y Petronilo Monroy, Los bermanos pintores de Tenancingo. Toluca, Instituto Mexiquense de Cultura, I995.

Siqueiros/Pollock, Pollock/Siqueiros. Catálogo de la exposición de la Kunsthalle de Düsseldorf, compilación y ensayo introductorio de Jurgen Harten, Düsseldorf, Dumont Verlag-Kunsthalle Düsseldorf, 1995, 2 vols.

Subasta de la colección de la biblioteca de la Hacienda de la Gavia. 20 T 2. de septiembre de 1995, México, Galerías Louis C. Morton, 1995.

Subasta de la coleción del Ing Mario Collignon de la Peña. 30 de septiembre y 10 de octubre de 1995, México, Galerías Louis C. Morton, 1995

Subasta de la colección de muebles y artes decorativas de la Hacienda de la Gavia. México, Galerías Louis C Morton, 1995

Subasta de la colección de pintura de la Hacienda de la Gavia (óleos, acuarelas, grabados y dibujos). México, Galerías Louis C. Morton, I995. 
Subasta de libros, grabados, documentos, autógrafos y condecoraciones. 23 de noviembre de 1995, México. Galerías Louis C. Morton, I995.

Subasta de relojes de bolsillo de la colección Arechavala. 2.6 de noviembre de 1995 , México, Galerías Louis C. Morton, 1995.

Subasta de charreria, tauromaquia y paisaje 28 de junio de 1995 , México, Galerías Louis C. Morton, 1995.

Subasta selecta de antigüedades. I8 de julio de 1995, México, Galerías Louis C Morton, 1995 .

Tibol, Raquel, Rufino Tamayo. Del reflejo al sueño Iq20-Ig5o. Catálogo de la exposición del Centro Cultural Arte Contemporáneo, México, Fundación Cultural Televisa, 1995

Tovar de Teresa, Guillermo, Repertorio de artistas en México. México, Grupo Financiero Bancomer, 1995, vol. I: A-Z.

La tradición del amate. inovación y protesta en el arte mexicano. México, La Casa de las Imágenes, 1995.

Vallarino, Roberto, El caballito de Sebastián Historia de una escultura monumental urbana. México, Ediciones del Equilibrista, 1995.

Wolfgang Paalen Retrospectiva. Catálogo de la exposición del Museo de Arte Contemporáneo Alvar y Carmen $\mathrm{T}$ de Carrillo Gil, México, Consejo Nacional para la Cultura y las Artes-Instituto Nacional de Bellas Artes, 1994

Zalce total Catálogo de la exposición del Museo del Palacio de Bellas Artes, ensayo introductorio de Albetto Híjar, México, Consejo Nacional para la Cultura y las Artes-Instituto Nacional de Bellas Artes, 1995.
Arte colonial

Andalucia en América: el legado de ultramar. Madrid, El Legado Andalusi, 1995.

Arcelus de Diego, María Soledad, Estudios de los barnices en la pintura colonial. México, Instituto Nacional de Antropología e Historia, 1995.

Armella de Aspe, Virginia, Testimonios artísticos de la evangelización. México, Gutsa, 1995

Burgos Villanueva, Francisco Rafael, $E l$ Olimpo. Un predio colonial en el lado poniente de la plaza mayor de Mérida, Yucatán, y análisis cerámico comparativo. México, Instituto Nacional de Antropología e Historia, 1995.

Couto, José Bernardo, Diálogo sobre la historia de la pintura en México. Estudio introductorio de Juana Gutiérrez Haces y notas de Rogelio Ruiz Gomar, México, Consejo Nacional para la Cultuta y las Artes, 1995.

Florencia, Francisco de, y Juan Antonio de Oviedo, Zodiaco mariano. Introducción de Antonio Rubial García, México, Consejo Nacional para la Cultura y las Artes-Sello Bermejo, r995

Garrido Cardona, Martha Lis, Monumentos coloniales religiosos del istmo de Tehuantepec. México, Instituto Nacional de Antropología e Historia, 1995

González Franco, Glorinela, Artistas y artesanos a través de fuentes documentales. México, Instituto Nacional de Antropología e Histoiia, 1995, 2 vols.

Gruzinski, Serge, La guevra de las imágenes. De Cristóbal Colon a Blade Runner, I492-2019. México, Fondo de Cultura Económica, 1995

Imprentas, ediciones y grabados de México barroco. México, Museo Amparo, I995. 
Lucas Anaya, José, La milagrosa aparición de Nuestra Señora Maria de Guadalupe de México México, Universidad Nacional Autónoma de México, 1995

Luna, Carlos, Mi madre, mi patria $=M y$ Mother, My Land México, Museo Amparo, 1995 .

Maldonado Mares, Rubén, y Raquel Pineda, Catálogos de Documentos de Arte, I8. Archivo General de la Nación. Ramo matrimonios, tercera parte. México, Universidad Nacional Autónoma de México-Instituto de Investigaciones Estéticas, 1995.

Maquívar, María del Consuelo, El imaginero novohispano y su obra. las esculturas de Tepotzotlán. México, Instituto Nacional de Antropología e Historia, 1995.

Martínez Chinas, Rosalino, La colección de armas del Museo Nacional de Historia. México, Instituto Nacional de Antropología e Historia, 1995.

Maza, Luis Reyes de la, Juan Xochilt I el pontifice mexicano. México, L Reyes de la Maza, 1995.

Moncada, José Omar, El ingeniero Miguel Consianzó Un militas ilustrado en la Nueva España. México, Universidad Nacional Autónoma de México, 1995.

El mudéjar iberoatnericano del islam al nuevo mundo. Granada, El Legado Andalusi, 1995.

Sebastián, Santiago, Mariano Monterrosa y José Antonio Terán, Iconografía del arte del siglo XVT en México. Zacatecas, Universidad Autónoma de Zacatecas, 1995.

Stresser Pean, Guy, El códice de Xicotepec estudio e interpretación. México, Gobierno del Estado de Puebla, I995.

Tovar de Teresa, Guillermo, Miguel Cabrera. México, Banco Mexicano, 1995.
Victoria, José Guadalupe, comp., Una bibliografia de arte novohispano. México, Universidad Nacional Autónoma de México-Instituto de Investigaciones Estéticas, I995.

\section{Arte prehispánico}

Alcina Franch, José, Arqueólogos o anticuarios historia antigua de la arqueologia en la Américi española Barcelona, Serbal, 1995.

Castillo Peña, Patricia, La expresión simbólica del Tajín. México, Instituto Nacional de Antropología e Historia, 1995.

Fuente, Beatriz, de la, comp., La pintura mural prehispánica en México I. Teotibuacan. Tomo I Catálogo México, Universidad Nacional Autónoma de México, 1995 .

Garza, Mercedes de la, Aves sagradas de los mayas. México, Universidad Nacional Autónoma de México, 1995.

Hasselkus M., Hans, Mi cuaderno de notas. el tablero de los go glifos de Palenque. México, H. Hasselkus, 1995

Matos Moctezuma, Eduardo, Tesori D'Arte in Messico. Milán, Instituto Geográfico de Agostini, I995

Matos Moctezuma, Eduardo, et al., Dioses del México antiguo. Catálogo de la exposición del Antiguo Colegio de San Ildefonso, México, Consejo Nacional para la Cultura y las Artes-Universidad Nacional Autónoma de México-Instituto Nacional Antropología e Historia, 1995

Miller, Arthur G., The Painted Tombs of Oaxaca, Mexico: Living with the Dead. Cambridge, Cambridge University, 1995 
Museo de la cultura teotibuacand guía. México, Instituto Cultural Domec, I995.

The Olmec and their Neighbors. Essays in Memory of Matthew W. Siegfried Princeton, Princeton University-The Art Museum, i995

La pirámide del Sol, Teotihuacan antologia. México, Instituto Cultural Domec, 1995.

Salinas Flores, Óscar, Tecnología y diseño en el México prehispánico. México, Universidad Nacional Autónoma de MéxicoFacultad de Arquitectura, 1995

Š́gota, Dúrdica, Valores plásticos del arte mexica México, Universidad Nacional Autónoma de México-Instituto de Investigaciones Estéticas, 1995.

Solís, Felipe, y Martha Carmona M, El oro precolombino de México. Colecciones mixteca y azteca. México, Ixe, I995.

Stone, Andrea J., Images from the Underworld: Naj Tunich and the Tradition of Maya Painting. Austin, University of Texas, I995.

\section{Fotografia}

Franz Mayer: fotógrafo. México, Museo Ftanz Mayer, 1995.

García Krinsky, Emma Cecilia, Kati Horna. Recuento de una obra. México, Consejo Nacional para la Cultuia y las Artes, 1995

Luz y tiempo. Colección fotográfica formada por Manuel Alvarez Bravo para la Fundación Cultural Televisa, A. C Presentación de Roberto R Littman, México, Fundación Cultural Televisa, I995.

Meyer, Pedro, Verdades y ficciones: un viaje de la fotografia documental a la digital. México, Casa de las Imágenes, 1995.
Pacheco, Cristina, La luz de México. Entrevistas con pintores y fotógrafos. México, Fondo de Cultura Económica, 1995.

\section{Varios temas}

El arte y la vida cotidiana. XVI Coloquio Internacional de Historia del Avte. México, Universidad Nacional Autónpma de México-Instituto de Investigaciones Estéticas, 1995

Arte y violencia XVIII Coloquio Internacional de Historia del arte. México, Universidad Nacional Autónoma de MéxicoInstituto de Investigaciones Estéticas, 1995 .

Cien años de cine. Una historia del line en cien películas. México, Siglo Veintiuno, 1995, vol. 2.

La ciencia de las imágenes. México, Universidad Iberoamericana, I995.

Colección Instituto Cultural Cabañas. Guadalajara, Instituto Cultural Cabañas, 1995

Colección Pueblo de Jalisco. Guadalajara, Instituto Cultural Cabañas, 1995 .

Dallal, Alberto, La danza en México. Primera parte Panorama critico. México, Universidad Nacional Autónoma de México-Instituto de Investigaciones Estéticas, 1995 .

__, La danza en México. Tercera parte La danza escénica popular, 1877-1930. México, Universidad Nacional Autónoma de México-Instituto de Investigaciones Estéticas, 1995.

Diálogos sobre ontología y estética. México, Universidad Nacional Autónoma de México, 1995.

De las estaciones. México, Museo Nacional de los Ferrocarriles Mexicanos, 1995. 


\section{6}

Los discursos sobre el arte. XV Coloquio Internacional de Historia del Arte. México. Universidad Nacional Autónoma de México-Instituto de Investigaciones Estéticas, 1995 .

El estado de Quintana Roo. México, Azabache, I995,

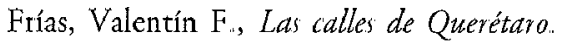
México, Gobierno del Estado de Querétaro, 1995

Germán R, María Teresa, Iconografia botánica del siglo XIX del Herbario Nacional de México. Ilustraciones de A. Unzueta,

A. Tenorio y J. Ma. Velasco, México, Universidad Nacional Autónoma de México, 1995 .

Introducción a la cultura artística de México (literatura, música, danza, artes plásticas, teatro, arquitectura, artes visuales). México, Secretaría de Educación PúblicaConsejo Nacional para la Cultura y las Artes, 1995.

Mierovich, Clara, Vicente T. Mendoza artista y primer folclórico musical. México, Universidad Nacional Autónoma de México, 1995.

Ramírez Montes, Mina, Catálogos de Documentos de Arte 19 Colección Manuel Toussaint. México, Universidad Nacional Autónoma de México, 1995.
Ramos Galicia, Yolanda, Muestra de arte popular tlaxcalteca. México, Instituto Nacional de Antropología e Historia, r995.

Tavares López, Edgar, Colonia Roma. México, Clío, 1995

Tovar de Teresa, Guillermo, y Efraín Castro Morales, El arte de la herrería en México México, Grupo Financiero Bancomer, I995.

Vestigios de Tierra Santa. Del Museo de Israel. Catálogo de exposición, México, Centro Cultural Arte Contemporáneo, I995.

\section{Revistas}

Arquitectura, número I3, México, agostoseptiembre de 1995

Artes de México, núm 28, "La falsificación y sus espejos"; núm. 29, "Visiones de Guadalupe", México, 1995.

Cuadernos de Arquitectura Virreinal, División de Estudios de Posgrado, Facultad de Arquitectura, unam, México, 1995, núm. 16

Luna Córnea. Centro de la imagen, Consejo Nacional para la Cultura y las Artes, México, 1995, núm. 7. \$ 